\title{
Effects of selective inhibition of cyclooxygenase and lipooxygenase pathways in follicle rupture and ovulation in the rat
}

\author{
M Gaytán, C Bellido, C Morales, J E Sánchez-Criado and F Gaytán \\ Department of Cell Biology, Physiology and Immunology and ${ }^{1}$ Department of Pathology, School of Medicine, \\ University of Córdoba, Avda Menendez-Pidal s/n, 14004 Cordoba, Spain
}

Correspondence should be addressed to M Gaytán; Email: bc1galuf@uco.es

\begin{abstract}
Treatment with non-steroidal anti-inflammatory drugs, either non-selective or selective cyclooxygenase-2 (COX-2) inhibitors, consistently impairs ovulation, indicating the essential role of COX-2/prostaglandins in the ovulatory process. Indomethacin, a potent inhibitor of both COX-1 and COX-2, induced several ovulatory alterations, consisting of a decrease in the number of oocytes effectively ovulated, trapping of oocytes inside the luteinized follicle, as well as abnormal follicle rupture at the basolateral sides, with release of the oocyte and follicular fluid to the interstitium. Yet, the precise role of prostaglandins in ovulation and whether some of the ovulatory defects induced by indomethacin are due to interference with additional components of the ovulatory cascade, beyond prostaglandin synthesis, are not completely understood. We have used gonadotrophin-primed immature rats to analyse whether, compared to indomethacin, selective inhibition of COX-2, with or without concomitant inhibition of COX-1, or selective inhibition of the lipooxygenase (LOX) pathway, induce similar ovulatory alterations. Immature rats (27 days of age) were injected PMSG (10 IU), and 48 h later hCG (10 IU) subcutaneously, and different anti-inflammatory drugs. Animals were killed at $21 \mathrm{~h}$ after hCG injection. Rats treated with the selective COX-2 inhibitor NS398 $(10 \mathrm{mg} / \mathrm{kg}$ body weight, $(\mathrm{bw}))$ showed alterations in follicle rupture as those treated with indomethacin $(0.5 \mathrm{mg} / \mathrm{rat})$, albeit affecting a lower number of follicles, irrespective of the concomitant inhibition of COX-1 with the selective inhibitor SC560 $(10 \mathrm{mg} / \mathrm{kg} \mathrm{bw})$. Rats treated with the LOX inhibitor NDGA $(300 \mathrm{mg} / \mathrm{kg}$ bw) did not show ovulatory alterations. These data indicate that the characteristic alterations of follicle rupture induced by indomethacin, are also induced by selective COX-2 inhibitors, strengthening the contention that prostaglandins play a crucial role in the spatial targeting of follicle rupture at the apex.

Reproduction (2006) 132 571-577
\end{abstract}

\section{Introduction}

Ovulation is a complex, multistep process that is triggered in cycling females by the mid-cycle preovulatory LH surge. The gonadotrophin surge induces the coordinate expression of a plethora of genes, initiates a cascade of events, and finally results in follicle rupture and release of the mature oocyte from the ovary. One of the $\mathrm{LH}$-induced genes in preovulatory follicles is that encoding cyclooxygenase-2 (COX-2), the inducible isoform of the prostaglandin $\mathrm{G} / \mathrm{H}$ synthase, while the other main cyclooxygenase isoform, COX-1, is constitutively expressed (Sirois et al. 2004). A large body of evidence has accumulated, indicating the essential role of COX-2/prostaglandins in ovulation. In the first approach, classical non-steroidal anti-inflammatory drugs (NSAIDs), inhibiting both COX-1 and COX-2 activity, as well as the more recently developed selective COX-2 inhibitors, have been repeatedly reported to inhibit ovulation in all mammalian species investigated so far (reviewed by Brännström \& Janson 1991, Tsafriri et al. 1993, Espey \& Lipner 1994). Furthermore, exogenous prostaglandin supplementation restored ovulation in NSAID-treated animals, at least under some experimental conditions (Holmes et al. 1983, Sogn et al. 1987, Gaytán et al. 2002a). More recently, genetic studies in mice (Lim et al. 1997, Matsumoto et al. 2000) have confirmed the obligatory role of COX-2/ prostaglandins in ovulation. Mice with targeted deletion of COX-2, but not COX-1, show multiple reproductive alterations, including defective ovulation (Lim et al. 1997), that is restored by exogenous supplementation 
with prostaglandins of the E series (Davis et al. 1999). Furthermore, prostaglandin E2 receptor (subtype EP2)knockout mice also show defective ovulation (Ochsner et al. 2003). However, the molecular targets and the precise role of prostaglandins in the ovulatory process are not completely understood.

In most previous studies on COX-2 inhibition, ovulation rate has been evaluated by counting oocytes in the oviduct from $16 \mathrm{~h}$ after the preovulatory LH surge or hCG administration, and eventual histological analysis of randomly selected ovarian sections. Common features in NSAID-treated animals are decreased numbers of oocytes in the oviducts and the presence of oocytes trapped inside luteinizing follicles. On this basis, it is generally assumed that inhibition of follicle rupture is the mechanism underlying the anti-ovulatory effects of COX inhibitors (reviewed in Brännström \& Janson 1991, Tsafriri et al. 1993, Espey \& Lipner 1994). However, this assumption is closely linked to the method used to check ovulation. Although the presence of eggs in the oviduct provides unequivocal evidence on the occurrence of follicle rupture and ovulation, the absence of follicle rupture cannot be inferred from the lack of oviductal oocytes. Furthermore, the observation of randomly selected ovarian sections provided a limited view of the ovulatory process. This can be appreciated clearly by detailed histological examination of serially sectioned ovaries in rats treated during the ovulatory period with indomethacin (INDO), a potent inhibitor of both COX-1 and COX-2 (Vane et al. 1998). In these animals, about $1 /$ 3 of the cumulus-oocyte complexes (COCs) remained trapped inside the luteinized follicle, about $1 / 3$ are released to the ovarian interstitium through ruptures at the basolateral follicle sides, and about $1 / 3$ are effectively ovulated (Gaytán et al. 2002a,b, 2003). Furthermore, some of the luteinizing follicles with trapped COCs show rupture of the follicle wall at the basolateral sides, with release of follicular fluid into the ovarian interstitium. In addition, the release of follicular fluid and granulosa cells to the ovarian interstitium, leads to invasion of the ovarian stroma, rupture of blood and lymphatic vessels, hemorrhagia and formation of emboli of follicular fluid and granulosa cells (Gaytán et al. $2002 a, b, 2003)$. These data indicate that induction of abnormal (misdirected) follicle rupture, rather than absence of follicle rupture, seems to be the main ovulatory alteration in INDO-treated rats.

Although the anti-ovulatory effects of NSAIDs are attributed to COX-2 inhibition, some studies have found a poor correlation between the inhibition of prostaglandin synthesis and the inhibition of ovulation rate (reviewed by Espey \& Lipner 1994). This raises the possibility that some of the effects of INDO on follicle rupture and ovulation could be due to COX-2-independent actions. Previous studies have reported an effect of INDO on the lipooxygenase (LOX) pathway of arachidonic acid metabolism, and a decrease in the ovulation rate after selective inhibition of LOX pathway in rats (Mikuni et al. 1998). In addition, although genetic deletion of COX-1 does not inhibit ovulation (Langebach et al. 1995), and ovulatory impairment in INDO-treated animals seems to be due to COX-2 inhibition, it is not known whether concomitant inhibition of COX-1 has a role in the induction of abnormal follicle rupture in these animals, since recent studies have reported that COX-1 is also involved in inflammation (Gilroy \& Colville-Nash 2000), and ovulation has been considered an inflammatory-like reaction (Espey 1980). In this context, we aimed to analyse whether the characteristic alterations of follicle rupture and ovulation present in INDO-treated rats were specifically related to COX-2 inhibition and if they are also related to concomitant COX-1 inhibition, or to side effects of the interconnected LOX pathway.

\section{Materials and Methods}

\section{Animals and treatments}

Immature female Wistar rats were used for this study. The animals were maintained under controlled light $(14 \mathrm{~h}$ light: $10 \mathrm{~h}$ darkness) and temperature $\left(22^{\circ} \mathrm{C}\right)$ conditions, and given access to pelleted food and tap water ad libitum. The experiments were conducted in agreement with the National Institute of Health's Guide for the Care and Use of Laboratory Animals, and approved by the ethics committee of the University of Córdoba. Unless indicated, all products were purchased from Sigma. At 27 days of age (about $80 \mathrm{~g}$ body weight (bw)), the animals were injected, subcutaneously, 10 IU PMSG at $1200 \mathrm{~h}$, and $48 \mathrm{~h}$ later $10 \mathrm{IU}$ hCG, to induce follicle development and ovulation respectively. The animals were divided into six groups that were injected (at the same time as hCG injection) s.c. with: (i) vehicle (olive oil, $200 \mu \mathrm{l}$ ); (ii) indomethacin $(0.5 \mathrm{mg} / \mathrm{rat})$, a non-selective COX inhibitor, inhibiting both COX-1 and COX-2 activity; (iii) NS398 (10 mg/kg), a selective COX-2 inhibitor; (iv) SC560 (10 mg/kg), a selective COX-1 inhibitor; (v) NS398 $(10 \mathrm{mg} / \mathrm{kg})$ plus SC560 (10 mg/kg), to inhibit both COX-1 and COX-2; and (vi) nordihydroguaiaretic acid (NDGA; $300 \mathrm{mg} / \mathrm{kg}$ ), a selective inhibitor of the lipooxygenase pathway. The doses were selected based on previous studies reporting inhibition of enzyme activity and/or ovulation in rats (Mikuni et al. 1998, Sakurai et al. 2003, Gaytán et al. 2004) and in the range of selectivity. All the animals were killed $21 \mathrm{~h}$ after hCG injection.

\section{Histological procedures and evaluation of follicle rupture and ovulation}

The ovaries, including the oviducts and periovarian fat pads were dissected, fixed with Bouin-Hollande's fluid for $24 \mathrm{~h}$ and embedded in paraffin wax after dehydration. Serial, $6 \mu \mathrm{m}$-thick, sections were cut, stained with haematoxylin and eosin, and viewed under the 
microscope. Twenty-one hours after hCG treatment, the corpora lutea are not completely luteinized, and could be considered as luteinizing follicles, particularly when unruptured and containing the COC. Accordingly, the term luteinized follicles has been adopted, irrespective of the presence or absence of follicle rupture and release of the COC. In each ovary, all serial sections were viewed under the microscope, and the total number of luteinized follicles was counted. The number and location of COCs (either in the oviduct, inside the luteinized follicle or at the ovarian interstitium) were recorded. The number of COCs in each location was presented as a percentage, with respect to the total numbers of luteinized follicles per animal (that matched the total number of COCs per animal). No significant differences were found among groups with respect to the mean number of luteinized follicles/COCs per animal (ranging from $13.4 \pm 1.3$ to $15.4 \pm 1.2$, mean \pm s.E.M. for $n=5)$. Statistical analysis was performed by ANOVA and Student-Newmann-Keuls for multiple comparisons among means, and significance was considered at the 0.05 level.

\section{Results}

Rats treated with vehicle or selective COX-1 inhibitor SC560, showed newly formed corpora lutea, COCs in the oviduct, and no alterations of the ovulatory process. In contrast, rats treated with INDO, NS398 or NS398 plus SC560, showed altered follicle rupture and ovulation that were more frequently observed in INDO-treated rats. Ovulatory defects in these animals, included trapping of the expanded COC inside the luteinized follicles (Fig. 1a,b), and abnormal follicle rupture at the basolateral sides, with release of the $\mathrm{COC}$ to the ovarian interstitium (Fig. 1c-f). Irrespective of the location of the COCs, the oocytes were in the metaphase Il stage, and showed expanded cumulus (Fig. 1a-f) in all groups. Additional alterations such as rupture of blood vessels and blood extravasations were commonly observed around interstitial COCs (Fig. 1c-f) because of the release of the $\mathrm{COC}$ and follicular fluid to the ovarian interstitium, through basolateral follicle sides, in rats treated with COX-2 inhibitors. Less frequently, invasion of the ovarian bursa, with infiltration of the periovarian fat pad by granulosa cells (Fig. 1g) was observed. Otherwise, rats treated with the LOX inhibitor NDGA, did not show alterations of the ovulatory process, and COCs were located in the oviduct (Fig. 1h), although the ovarian medulla showed extensive oedema (Fig. 1i).

The quantitative data are presented in Figs 2-4. The numbers of oocytes effectively ovulated (Fig. 2), i.e. located at the oviduct, were significantly decreased in rats treated with COX-2 inhibitors: INDO, NS398 and NS398 plus SC560. This ovulatory inhibition was significantly higher in INDO-treated rats (about 50\% decrease), than NS398-treated rats (about 25\% decrease), irrespective of concomitant treatment with the COX-1 inhibitor SC560. Comparison of the percentage of COCs trapped inside the luteinized follicle after COX-2 inhibition is shown in Fig. 3. No significant difference existed among animals treated with INDO, NS398 or NS398 plus SC560. In contrast, the percentage of COCs released to the ovarian interstitium through basolateral follicle ruptures (Fig. 4) was significantly higher in INDO-treated (about 27\% of the COCs) than NS398-treated rats (about $7 \%$ of the COCs), irrespective of the concomitant inhibition of COX-1 in NS398treated animals.

\section{Discussion}

Treatment with indomethacin (INDO) causes ovulatory dysfunction, characterized by the occurrence of abnormal rupture of some follicles at the basolateral follicle sides, with release of the cumulus-oocyte complex (COC), granulosa cells and follicular fluid to the ovarian interstitium, while other COCs remain trapped inside the corpus luteum, or released to the periovarian space, i.e. effectively ovulated (Gaytán et al. 2002a,b, 2003). This raises the possibility that some of the effects of INDO in ovulation could be due to the interference with ovulation-related mechanisms, others than COX-2/ prostaglandin synthesis inhibition. For instance, although INDO effects have been attributed to COX-2 inhibition (Sirois et al. 2004), it is not known whether concomitant inhibition of COX-1 could also play a role in abnormal follicle rupture. Detailed morphological studies in COX-2-knockout mice have not been published, and double COX-1/COX-2-knockout mice do not survive up to reproductive age (Reese et al. 2001). The data from this study indicate that all the characteristic alterations of follicle rupture and ovulation observed in INDO-treated rats are also present, albeit in a lower proportion of follicles, after selective COX-2 inhibition by treatment with NS398. In addition, concomitant treatment with the selective COX-1 inhibitor SC560 did not increase the anti-ovulatory effects of NS398-treated rats, reinforcing the contention that ovulatory defects in INDO-treated rats were due to COX-2 inhibition. This is also in agreement with the lack of ovulatory defects in rats treated with the selective COX-1 inhibitor SC560, reported here, and with the normal ovarian phenotype in COX-1-knockout mice (Langebach et al. 1995). Quantitative differences found in this study between non-selective (INDO) and selective (NS398) COX-2 inhibitors could be due to differences in their relative potency and/or pharmacokinetics.

Inhibition of the LOX pathway with the selective inhibitor NDGA, did not affect ovulation, and the only morphological alteration in these animals was the presence of extensive oedema of the ovarian medulla. Previous studies have provided contradictory results with 

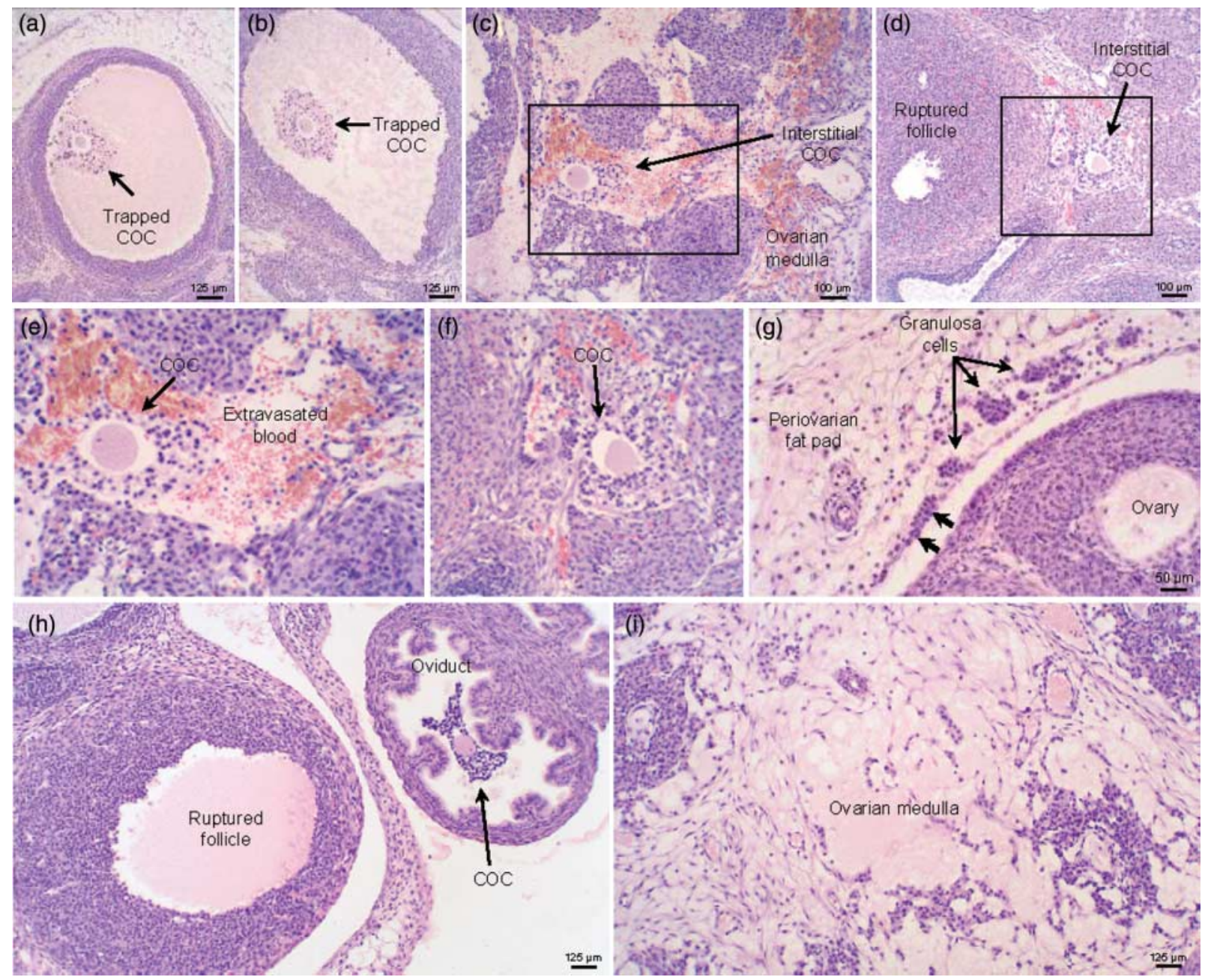

Figure 1 Representative micrographs from the ovary of rats treated with indomethacin (a, c, e), NS398 (b, d, f), NS398 plus SC560 (g) or NDGA (h,i), showing trapping of the expanded cumulus-oocyte complex $(C O C)$ inside the luteinized follicle $(a, b)$, release of the COC to the ovarian interstitium (c, d; the boxed areas are shown at higher magnification in e, $\mathrm{f}$ ), invasion of the ovarian bursa and periovarian fat pad by granulosa cells ( $\mathrm{g}$ ), normal ruptured follicles and location of the COC in the oviduct (h), as well as extensive oedema of the ovarian medulla (i).Haematoxylin and eosin.

respect to the effects of LOX inhibitors on ovulation, ranging from inhibition (Reich et al. 1983, Yoshimura etal. 1991, Mikuni et al. 1998) to lack of effects (Carvalho et al. 1989) or to an increased rate of ovulation (Hellberg et al. 1990). These discrepancies could be due to the existence of interactions and overlapping functions in ovulation of both arachidonic acid metabolism pathways (Mikuni et al. 1998). The treatment with NDGA has been reported to reduce prostaglandin synthesis in the ovary (Mikuni et al. 1998), and some of the reported effects of LOX inhibitors on ovulation could be related to side effects on the COX pathway. Furthermore, LOX-derived products seem to play a less relevant role than prostaglandins in ovulation (Hellberg et al. 1990).

The present view of the ovulatory process decrees that proteolytic degradation of the extracellular matrix is needed to allow rupture of the follicle wall (Tsafriri et al. 1993, Espey \& Lipner 1994, Curry et al. 2001). This implies that focalised proteolysis at the follicle apex (i.e. the follicle side facing the ovarian surface) is required to achieve effective ovulation (Reich et al. 1985a,b, 1991, Ny et al. 2002). Yet, the mechanisms responsible for the spatial targeting of follicle rupture at the apex are not known. Previous studies on several ovulation-related biochemical events (Espey \& Richards 2002), including the expression of specific matrix metalloproteinases (Bakke et al. 2004), have not reported the existence of polarisation (i.e. differential expression at the apex versus the base) in preovulatory follicles. It is also evident, that the presence of apical tissues, such as the ovarian surface epithelium or the tunica albuginea, are not essential for follicle rupture, as it happens in INDOtreated rats at the basolateral follicle sides. In this context, still unknown mechanisms could be responsible for the focalised proteolysis and subsequent rupture from preovulatory follicles at the apical zone. The data of this, and previous studies (Osman \& Dullaart 1976, Gaytán et al. 2002a,b, 2003), demonstrate that misdirected 


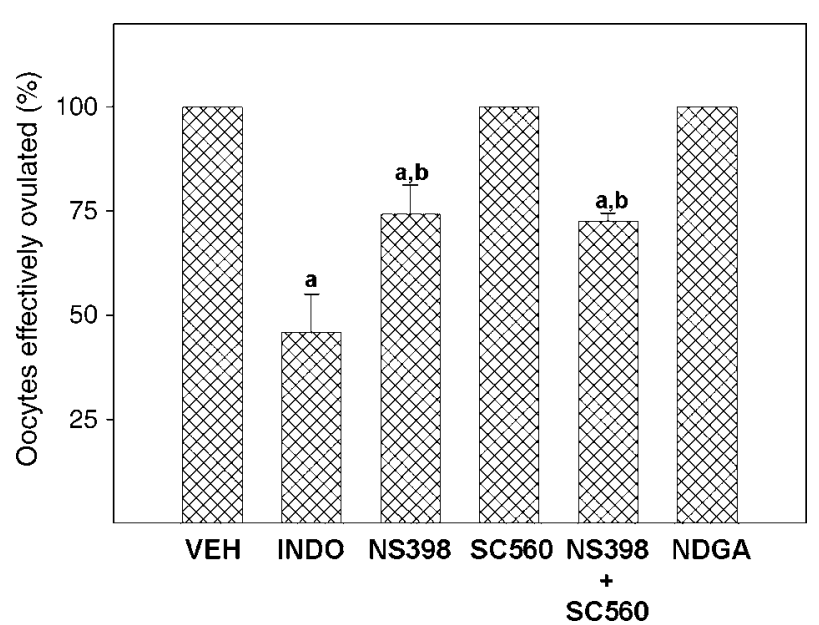

Figure 2 Percentage of oocytes effectively ovulated after treatment with vehicle (VEH), INDO (a dual NSAID), NS398 (a selective COX-2 inhibitor), SC560 (a selective COX-1 inhibitor), NS398 plus SC560, or NDGA (a selective LOX inhibitor). (a) $P<0.05$ vs vehicle; (b) $P<0.05$ vs INDO. ANOVA and Student-Newmann-Keuls for $n=5$ ).

follicle rupture occurs after pharmacological COX-2 inhibition. The only well-characterized target of prostaglandins in preovulatory follicles is the tumour necrosis factor-activated gene-6 (TSG-6), which is dependent on the expression of COX-2 in cumulus cells in response to the preovulatory LH surge (Joyce et al. 2001), and codifies a hyaluronan-binding protein that participates in cumulus expansion (Richards 2005). Defective cumulus expansion, due to the lack of expression of TSG-6, has been considered as a possible cause of the anti-ovulatory effects of COX-2 inhibitors, as well as a component of the anovulatory ovarian phenotype of COX-2- and EP2-knockout mice (Hizaki et al. 1999, Ochsner et al.

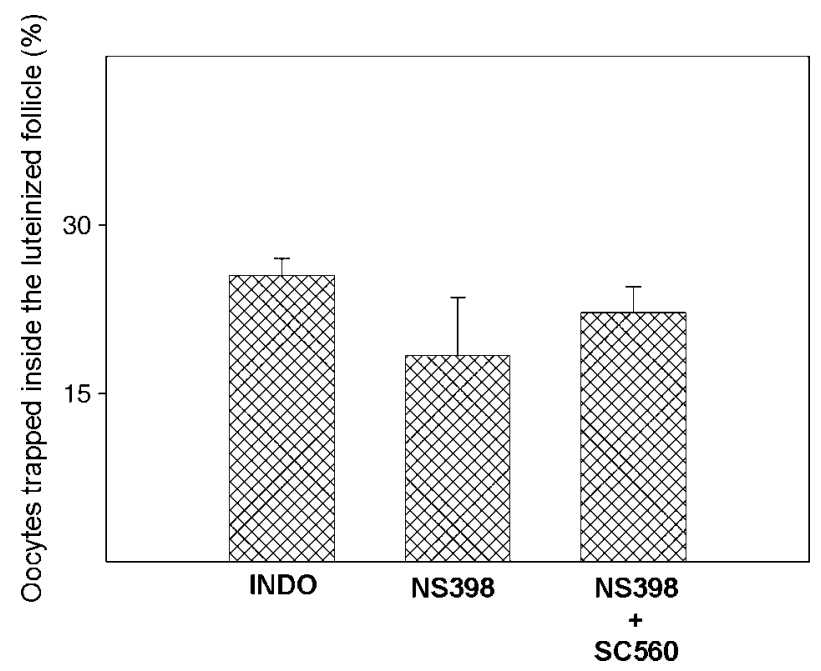

Figure 3 Comparison of the percentages of oocytes trapped inside the corpus luteum after treatment with INDO (a dual NSAID), NS398 (a selective COX-2 inhibitor), or NS398 plus SC560 (a selective COX-1 inhibitor). No significant difference existed among groups (ANOVA for $n=5$ ).

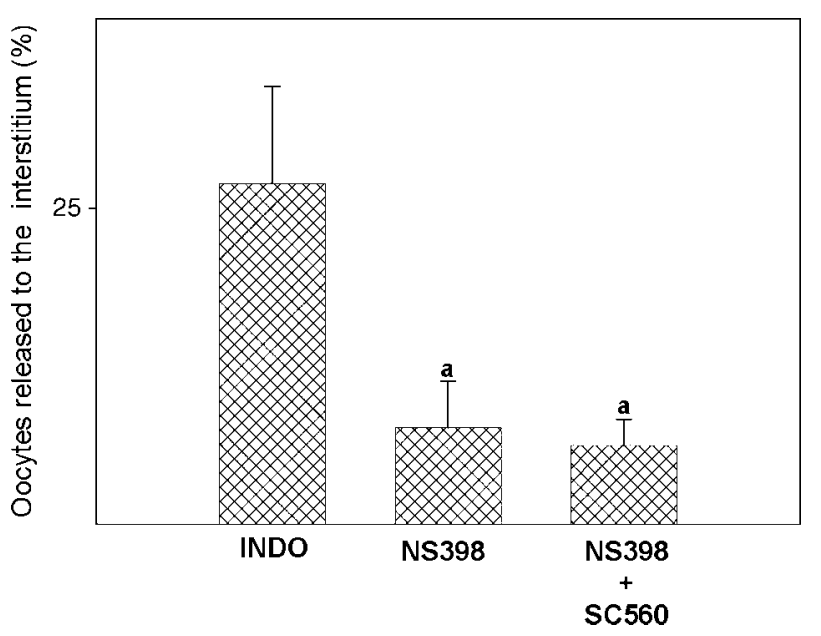

Figure 4 Comparison of the percentages of oocytes released to the ovarian interstitium after treatment with INDO (a dual NSAID), NS398 (a selective COX-2 inhibitor), or NS398 plus SC560 (a selective COX-1 inhibitor). A $P<0.05$ vs INDO (ANOVA and StudentNewmann-Keuls for $n=5$ ).

2003, Richards 2005). Morphological cumulus expansion was evident in NSAID-treated rats (see Fig. 1), although the existence of functional defects, possibly contributing to the trapping of some COCs inside the luteinizing follicle, cannot be discarded. However, defective cumulus expansion can hardly explain the occurrence of basolateral ruptures of the follicle wall and the release of the COC to the interstitium. In this sense, the anti-ovulatory effects of COX-2 inhibitors seem to be mainly due to the disruption of the mechanisms responsible for the spatial targeting of proteolytic activity/follicle rupture at the apex. It is worthwhile noting that follicle rupture at the apex was not selectively inhibited after COX-2 inhibition, and 50 $75 \%$ of oocytes were effectively ovulated. The presence of some ovulated oocytes even with the highest possible INDO dosages (Espey \& Lipner 1994) or in COX-2- or EP2-knockout mice (Russell \& Richards 1997, Ochsner et al. 2003) has been interpreted as evidence of the role of other inflammatory-related mechanisms, beyond prostanoid synthesis, in the ovulatory process (Mikuni et al. 1998). Without diminishing the possible relevance of prostaglandin-independent mechanisms, the lack of a complete inhibition of ovulation after pharmacological of genetic disruption of COX-2 activity can be explained by the apparent role of prostaglandins, preventing follicle rupture at the basolateral follicle sides. Under this hypothesis, COX-2 inhibition allows rupture of the follicle at any site of the follicle wall, including the apex. However, NSAIDs are pleiotropic drugs displaying many COX-independent effects (Tegeder et al. 2001). The possible effects of the activation of COX-independent factors, either alone or in combination with COX-2 inhibition, on the ovulatory process are largely unexplored and whether COX-2-independent actions of NSAIDs 
account for part of the anti-ovulatory effects of these drugs is yet to be determined.

It has been previously reported that gonadotrophinprimed immature rats (GPIR) show ovulatory defects identical to that found in adult INDO-treated ones, when ovulation was induced before 25 days of age (Gaytán et al. 2004), suggesting that the mechanisms responsible for follicle rupture at the apex are not fully established in very young rats. In this study, ovulation was induced at 29 days of age, to avoid age-dependent ovulatory defects. In good agreement, vehicle-treated rats did not show ovulatory alterations.

A previous study (Tsafriri et al. 1989) has reported the intraovarian release of eggs into the follicular thecal compartment after intrabursal administration of antibodies to tissue-type plasminogen activator (tPA) and $\alpha 2$-anti-plasmin ( $\alpha 2 \mathrm{AP})$. It is not clear, whether the inhibition of plasmin activity shares a common mechanism with COX-2 inhibition in blocking ovulation. In the rat, INDO doses that inhibit ovulation do not affect PA activity (Shimada et al. 1983, Reich et al. $1985 a, b)$, although higher INDO doses in the rat (Espey et al. 1985) or intrafollicular INDO injection in bovine preovulatory follicles (Li et al. 2006) has been reported to inhibit plasmin activity. Antibodies to tPA or $\alpha 2 \mathrm{AP}$ were effective in suppressing ovulation only when injected at the same time of hCG administration (Tsafriri et al. 1989), however, INDO blocks ovulation over a broad period of time, from $10 \mathrm{~h}$ before, to $13 \mathrm{~h}$ after hCG administration (Tanaka et al. 1992), suggesting that suppression of plasmin activity and COX-2 inhibition act at different levels in the ovulatory cascade.

In summary, abnormal follicle rupture (that seems to be the keystone of the antiovulatory effects of indomethacin) also occurred after selective COX-2 inhibition and was not influenced by concomitant selective inhibition of COX-1 or inhibition of the lipooxygenase pathway. NSAIDs are one of the most frequently used drugs, due to their analgesic, antiinflammatory and anti-tumoural properties. Selective COX-2 inhibitors have been recently generated in order to avoid the undesirable side effects mediated by COX- 1 inhibition. The data from this study indicate that, in addition to the well-known antiovulatory effects, the induction of abnormal follicle rupture is also induced by treatment with selective COX-2 inhibitors.

\section{Acknowledgements}

The authors are very grateful to $\mathrm{E}$ Tarradas and $\mathrm{T}$ Recio for their technical assistance. This work has been subsidized by Grant BFU 2005-01443 ER $\alpha$-ER $\beta$. The authors declare that there is no conflict of interest that would prejudice the impartiality of this scientific work.

\section{References}

Bakke LJ, Li Q, Cassar CA, Dow MPD, Pursley JR \& Smith GW 2004 Gonadotropin surge-induced differential upregulation of collagenase-1 (MMP-1) and collagenase-3 (MMP-13) mRNA and protein in bovine preovulatory follicles. Biology of Reproduction 71 605-612.

Brännström M \& Janson PO 1991 The biochemistry of ovulation. In Ovarian Endocrinology, pp 132-166. Ed. SG Hillier. Oxford: Blackwell Scientific Publications.

Carvalho CB, Yeik BS \& Murdoch WJ 1989 Significance of follicular cyclooxygenase and lipooxygenase pathways of metabolism of arachidonate in sheep. Prostaglandins 37 553-558.

Curry TE Jr, Song L \& Wheeler SE 2001 Cellular localization of gelatinases and tisssue inhibitors of metalloproteinases during follicular growth, ovulation, and early luteal formation in the rat. Biology of Reproduction 65 855-865.

Davis BJ, Lennard DE, Lee CA, Tiano HF, Morham SG, Wetsel WC \& Langenbach R 1999 Anovulation in cyclooxygenase-2 deficient mice is restored by prostaglandin E2 and interleukin-1â. Endocrinology $1402685-2695$.

Espey LL 1980 Ovulation as an inflammatory reaction - a hypothesis. Biology of Reproduction 22 73-106.

Espey LL, Shimada H, Okamura H \& Mori T 1985 Effect of various agents on ovarian plasminogen activator activity during ovulation in pregnant mare's serum gonadotropin-primed immature rats. Biology of Reproduction 32 1087-1094.

Espey LL \& Lipner H 1994 Ovulation. In Physiology of Reproduction, pp 725-780. Eds E Knobil \& JD Neill. New York: Raven Press.

Espey LL \& Richards JS 2002 Temporal and spatial patterns of ovarian gene transcription following an ovulatory dose of gonadotropin in the rat. Biology of Reproduction 67 1662-1670.

Gaytán F, Tarradas E, Bellido C, Morales C \& Sánchez-Criado JE 2002a Prostaglandin E1 inhibits abnormal follicle rupture and restores ovulation in indomethacin-treated rats. Biology of Reproduction 67 1140-1147.

Gaytán F, Tarradas E, Morales C, Bellido C \& Sánchez-Criado JE 2002b Morphological evidence for uncontrolled proteolytic activity during the ovulatory process in indomethacin-treated rats. Reproduction 123 639-649.

Gaytán F, Bellido C, Gaytán M, Morales C \& Sánchez-Criado JE 2003 Differential effects of RU486 and indomethacin on follicle rupture during the ovulatory process in the rat. Biology of Reproduction 69 99-105.

Gaytán M, Bellido C, Morales C, Gonzalez-Padilla M, SanchezCriado JE \& Gaytan F 2004 Immature rats show ovulatory deffects similar tot hose in adult rats lacking prostaglandin and progesterone actions. Reproductive Biology and Endocrinology 2 63-74.

Gilroy DW \& Colville-Nash PR 2000 New insights into the role of COX-2 in inflammation. Journal of Molecular Medicine $\mathbf{7 8}$ 121-129.

Hellberg P, Holmes PV, Brannstrom M, Olofson J \& Janson PO 1990 Inhibitors of lipoxygenase increase the ovulation rate in the in-vitro perfused luteinizing hormone-stimulated rabbit ovary. Acta physiologica Scandinavica 128 557-564.

Hizaki H, Segi E, Sugimoto Y, Hirose M, Saji T, Ushibuki F, Matsuoka T, Noda Y, Tanaka T, Yoshida N, Narumiya S \& Ichikawa A 1999 Abortive expansion of the cumulus and impaired fertility in mice lacking the prostaglandin E receptor subtype EP2. PNAS 96 10501-10506.

Holmes PV, Janson PO, Sogn J, Källfelt B, LeMarie WJ, Ahrén KB, Cajander S \& Bjersing L 1983 Effects of prostaglandin-F2a and indomethacin on ovulation and steroid production in the isolated perfused rabbit ovary. Acta Endocrinologica 104 233-239.

Joyce IM, Pendola FL, O'Brien R \& Epigg JJ 2001 Regulation of prostaglandin endoperoxide synthase 2 messenger ribonucleic acid expression in mouse granulosa cells during ovulation. Endocrinology 142 3187-3197. 
Langebach RSG, Morham HF, Tiano CD, Loftin BI, Ghanayen PC, Chulada JF, Mahler CA, Lee EH, Goulding EH, Kluckman KD, Kim HS \& Smithies O 1995 Prostaglandin synthase 1 gene disruption in mice reduces arachidonic acid-induced inflammation and indomethacininduced gastric ulceration. Cell 83 483-492.

Li Q, Jimenez-Krassel F, Kobayashi Y, Ireland JJ \& Smith GW 2006 Effect of intrafollicular indomethacin injection on gonadotropin surge-induced expression of select extracellular matrix degrading enzymes and their inhibitors in bovine preovulatory follicles. Reproduction 131 533-543.

Lim H, Paria BC, Das SK, Dinchuck JE, Langenbach R, Trzaskos JM \& Dey SK 1997 Multiple female reproductive failures in cyclooxygenase 2-deficient mice. Cell 91 197-208.

Matsumoto H, Ma W, Smalley W, Trzaskos J, Breyer RM \& Dey SK 2000 Diversification of cyclooxygenase-2-derived prostaglandins in ovulation and implantation. Biology of Reproduction 64 1557-1565.

Mikuni M, Pall M, Peterson CM, Peterson CA, Hellberg P, Brännström M, Richards JS \& Hedin L 1998 The selective prostaglandin endoperoxide synthase-2 inhibitor, NS-398, reduces prostaglandin production and ovulation in vivo and in vitro in the rat. Biology of Reproduction 59 1077-1083.

Ny T, Wahlberg P \& Brändström IJM 2002 Matrix remodeling in the ovary: regulation and functional role of the plasminogen activator and matrix metalloproteinase systems. Molecular and Cellular Endocrinology 187 29-38.

Ochsner SA, Russell DL \& Richards JS 2003 Decreased expression of tumor necrosis factor- $\alpha$-stimulated gene 6 in cumulus cells of the cyclooxygenase-2 and EP2 null mice. Endocrinology 144 1008-1019.

Osman P \& Dullaart J 1976 Intraovarian release of eggs in the rat after indomethacin treatment at pro-oestrus. Journal of Reproduction and Fertility 47 101-103.

Reese J, Zhao X, Ma W, Brown N, Maziasz TJ \& Dey SK 2001 Comparative analysis of pharmacologic and/or genetic disruption of cyclooxygenase- 1 and cyclooxygenase- 2 function in female reproduction in mice. Endocrinology 142 3198-3206.

Reich R, Kohen F, Naor Z \& Tsafriri A 1983 Possible involvement of lipoxygenase products of arachidonic acid pathway in ovulation. Prostaglandins 26 1011-1020.

Reich R, Miskin R \& Tsafriri A 1985a Follicular plasminogen activator: involvement in ovulation. Endocrinology 116 516-521.

Reich R, Tsafriri A \& Mechanic GL 1985b The involvement of collagenolysis in ovulation in the rat. Endocrinology 116 522-527.

Reich R, Daphna-Iken D, Chun SY, Popliker M, Slager R, AdelmannGrill BC \& Tsafriri A 1991 Preovulatory changes in ovarian expression of collagenases and tissue metalloproteinase inhibitor messenger ribonucleic acid: role of eisosanoids. Endocrinology $\mathbf{1 2 9}$ 1869-1875.

Richards JS 2005 Ovulation: new factors that prepare the oocyte for fertilization. Molecular and Cellular Endocrinology 234 75-79.

Russell DL \& Richards JS 1997 Causes of infertility in mice with targeted deletion of the PGS-2 gene. Biology of Reproduction Supplementry. 178 (abstract 382)

Sakurai T, Tamura K, Okamoto S, Hara T \& Kogo H 2003 Possible role of cyclooxygenase II in the acquisition of ovarian luteal function in rodents. Biology of Reproduction 69 835-842.

Shimada H, Okamura H, Noda Y, Suzuki A, Tojo S \& Takada A 1983 Plasminogen activator in rat ovary during the ovulatory process: independence of prostaglandin mediation. Journal of Endocrinology 97 201-205.

Sirois J, Sayasith K, Brown KA, Stock A, Bouchard N \& Doré M 2004 Cyclooxygenase-2 and its role in ovulation: a 2004 account. Human Reproduction Update 10 373-385.

Sogn JH, Curry TEJr, Brännström M, LeMaire WJ, Koos RD, Papkoff H \& Janson PO 1987 Inhibition of follicle-stimulating hormoneinduced ovulation by indomethacin in the perfused rat ovary. Biology of Reproduction 36 536-542.

Tanaka N, Espey LL, Stacy S \& Okamura H 1992 Epostane and indomethacin actions on ovarian kallikrein and plasminogen activator activities during ovulation in the gonadotropin-primed immature rats. Biology of Reproduction 46 665-670.

Tegeder I, Pfeilschiffer J \& Geisslinger G 2001 Cyclooxygenaseindependent actions of cyclooxygenase inhibitors. FASEB Journal 15 2057-2072.

Tsafriri A, Bicsak TA, Cajander SB, Ny T \& Hsueh AJW 1989 Suppression of ovulation rate by antibodies to tissue-type plasminogen activator and $\alpha 2$ antiplasmin. Endocrinology 124 415-421.

Tsafriri A, Chun SY \& Reich R 1993 Follicular rupture and ovulation. In The ovary, pp 228-243. Eds EY Adashi \& PCK Leung. New York: Raven Press.

Vane JR, Bakhle YS \& Botting RM 1998 Cyclooxygenase 1 and 2. Annual Review of Pharmacology and Toxicology 38 97-120.

Yoshimura Y, Nakamura Y, Shiraki M, Hirota Y, Yamada H, Ando M, Ubukata Y \& Suzuki M 1991 Involvement of leukotriene B4 in ovulation in the rabbit. Endocrinology 129 193-199.

Received 17 April 2006

First decision 23 May 2006

Revised manuscript received 1 June 2006

Accepted 29 June 2006 